\title{
HUBUNGAN AKTIFITAS FISIK DENGAN KEJADIAN KEGEMUKAN PADA REMAJA DI JURUSAN GIZI POLITEKNIK KESEHATAN MATARAM
}

\section{(The relationship of physical activity with incidence of obesity in adolescents in the Nutrition Department of Health Polytechnic Ministry of Health Mataram)}

\author{
Retno Wahyuningsih ${ }^{1^{*}}$, Intan Gumilang Pratiwi ${ }^{2}$ \\ ${ }^{1}$ Jurusan Gizi Politeknik Kesehatan Kemenkes Mataram, Jln. Prabu Rangkasari, Dasan Cermen, Kel. Sandubaya, \\ Mataram, Indonesia. E-mail: khaylilaghina@gmail.com \\ ${ }^{2}$ Jurusan Kebidanan Politeknik Kesehatan Kemenkes Mataram, Jln. Prabu Rangkasari, Dasan Cermen, Kel. Sandubaya, \\ Mataram, Indonesia. E-mail: intangumil@gmail.com
}

\begin{abstract}
ABSTRAK
Kegemukan menjadi suatu permasalahan pada remaja putri, karena pada umumnya mereka ingin tampil sempurna dengan memiliki tubuh yang ideal, langsing dan ramping. Remaja yang kurang melakukan aktifitas fisik, seperti olahraga dan kegiatan-kegiatan yang membutuhkan banyak gerak tubuh merupakan hal yang harus diwaspadai terhadap terjadinya obesitas. Penelitian korelasional yang bertujuan untuk mengetahui hubungan aktifitas fisik dengan kejadian obesitas pada remaja di Jurusan Gizi Politeknik Kesehatan Mataram. Populasi penelitian ini adalah mahasiswa Jurusan Gizi yang terpilih secara acak sebanyak 62 orang. Data yang dikumpulkan yaitu aktivitas fisik yang diperoleh dari hasil recall aktivitas fisik selama $2 \times 24$ jam yang dilakukan selama dua hari yaitu hari kuliah dan hari libur kuliah (weekend). Pengukuran aktivitas fisik tersebut dengan menggunakan instrument PAL (Physical Activity Level). Analisis data menggunakan uji chi-square dan OR pada CI 95\%. Hasil penelitian diketahui remaja mempunyai aktifitas fisik yang sedang, namun IMT cenderung gemuk (28,2), dan terdapat hubungan signfikan (nilai $p=0,048$; $O R=3,3$ ) antara aktifitas fisik dengan IMT remaja mahasiswa. Aktifitas fisik ringan berpeluang sebesar 3,3 kali mengakibatkan obesitas dibandingkan aktifitas fisik sedang. Kesimpulan, aktifitas fisik remaja menunjukkan hubungan secara signifikan dengan indeks masa tubuh.
\end{abstract}

Kata kunci: Aktifitas fisik, IMT, obesitas, remaja

\begin{abstract}
Overweight becomes a problem in young women, because in general they want to look perfect by having an ideal body, slim and slim. Teenagers who lack physical activities, such as sports and activities that require a lot of body movement are things to watch out for obesity. This
\end{abstract}

*Penulis untuk korespondensi: khaylilaghina@gmail.com research is a correlational study that aims to determine the relationship of physical activity with the incidence of obesity in adolescents in the Department of Nutrition Health Polytechnic Mataram. The study population was all students of the Nutrition Department. The sample that was selected randomly as many as 62 students from the Department of Nutrition. Data collected were physical activities obtained from the recall of $2 \times 24$ hours of physical activity conducted over two days, namely college days and holiday days (weekends). Measurement of physical activity using the PAL instrument (Physical Activity Level). Data analysis used chi-square test and $O R$ at $95 \%$ CI. The results showed that adolescents have moderate physical activity, but BMI tends to be obese $(28,2)$, and there is a significant relationship ( $p$ value $=$ 0,048; OR= 3,3) between physical activity and BMI of adolescent students. Mild physical activity has a 3.3-fold chance of obesity compared to moderate physical activity. In conclusion, adolescent physical activity shows a significant relationship with body mass index.

Keywords: BMI, physical activity, obesity, adolescents

\section{PENDAHULUAN}

Kegemukan menjadi suatu permasalahan pada remaja putri, karena pada umumnya mereka ingin tampil sempurna yang seringkali diartikan dengan memiliki tubuh yang ideal, langsing dan ramping. ${ }^{1}$ Remaja putri yang mengalami kegemukan berharap dapat membuat tubuhnya ideal, apalagi keinginan mereka untuk membuat tubuhnya ideal dengan melakukan aktifitas fisik berlebih dan banyak mengikuti kegiatan berolahraga. ${ }^{2}$ Remaja yang kurang melakukan aktifitas fisik, seperti olahraga dan melakukan 
kegiatan-kegiatan yang membutuhkan banyak gerak tubuh merupakan hal yang harus diwaspadai terhadap terjadinya obesitas. ${ }^{3,4}$

Badan kesehatan dunia yaitu WHO menyebutkan bahwa obesitas adalah penumpukan lemak yang berlebihan ataupun abnormal yang dapat mengganggu kesehatan. ${ }^{5}$ Selama tiga dekade prevalensi kegemukan dan obesitas telah meningkat secara substansial. Menurut survei Riset Kesehatan Dasar (Riskesdas), pada tahun 2013 anak usia 16-18 tahun yang menderita kegemukan mencapai $7,3 \%$ dan meningkat menjadi $9,5 \%$ pada tahun 2018, dan juga ditemukan sebesar 4,0\% remaja pada usia 16-18 tahun mengalami obesitas. ${ }^{6}$ Orang yang mengalami overweight/obesitas mempunyai resiko lebih tinggi untuk menderita berbagai penyakit seperti penyakit kardiovaskuler (kolesteroltinggi, dislipidemia, dan hipertensi), resistensi endokrin, dan diabetes mellitus tipe 2 yang merupakan penyakitpenyakit pembunuh utama manusia atau pemberi beban kesehatan yang tinggi. ${ }^{7}$

Menurut WHO, obesitas terjadi karena ketidakseimbangan antara asupan energi dan keluaran energi dalam jangka waktu lama sehingga terjadi penimbunan jaringan lemak yang berlebihan. Pada perempuan lebih rentan mengalami peningkatan simpanan lemak, umumnya perempuan mempunyai jumlah lemak lebih besar daripada laki-laki yaitu rata-rata $26,9 \%$ dari total berat badan perempuan. Sementara jumlah lemak pada laki-laki rata-rata $14,7 \%$. Kelebihan lemak pada perempuan terlihat pada bagian perut, dada, dan anggota tubuh bagian atas. Hal tersebut akan menyebabkan seorang remaja putri memiliki citra tubuh/penampilan yang tidak bagus, atau rasa percaya diri yang kurang. ${ }^{5}$

Menurut Hendra et al, bahwa faktor pola hidup, aktifitas fisik dan lingkungan juga berperan terhadap terjadinya obesitas, dari hasil penelitian terhadap 50 orang remaja obesitas didapatkan bahwa 12 orang remaja dengan presentase $24 \%$ yang mengalami obesitas berdasarkan faktor pola hidup, aktifitas fisik dan lingkungan. Kemajuan teknologi masa kini membuat para remaja lebih sering menghabiskan waktu dengan duduk berjam-jam memainkan smartphone, main komputer dan juga menonton
TV sehingga kurangnya melakukan aktifitas lainya seperti berenang atau olahraga lainnya. ${ }^{8}$

Aktifitas fisik yang tidak ada (kurangnya aktifitas fisik) merupakan faktor risiko untuk penyakit kronis, dan secara keseluruhan diperkirakan menyebabkan kematian secara global. Salah satu faktor penting yang berperan pada obesitas adalah aktifitas fisik. ${ }^{9}$ Obesitas bukan hanya terkait masalah banyaknya mengkonsumsi makanan tapi juga kurangnya aktifitas fisik. Seiring perkembangan zaman terjadi berbagai perubahan gaya hidup terutama pada aktifitas fisik. ${ }^{10}$

Pada obesitas salah satu faktor yang penting adalah aktifitas fisik karena obesitas bukan hanya terkait masalah banyaknya mengkonsumsi makanan tapi juga kurangnya aktifitas fisik. Menurun dan rendahnya aktifitas fisik dipercaya sebagai salah satu hal yang menyebabkan obesitas. ${ }^{11}$

\section{METODE}

Penelitian ini termasuk penelitian korelasional yang bertujuan untuk mengetahui hubungan aktifitas fisik dengan kejadian obesitas pada remaja di Jurusan Gizi Politeknik Kesehatan Mataram. Sampel penelitian berjumlah 62 remaja/mahasiswa yang telah terpilih secara acak pada Jurusan Gizi Politeknik Kesehatan Mataram.

Data yang dikumpulkan yaitu aktivitas fisik yang diperoleh dari hasil recall aktivitas fisik selama $2 \times 24$ jam. Recall tersebut dilakukan selama dua hari yaitu hari kuliah dan hari libur kuliah (weekend). Pengukuran aktivitas fisik yakni dengan menggunakan instrument PAL (physical activity level) yang merupakan hasil adaptasi dari jurnal internasional The Physical Activity Questionnaire for Older Children (PAQ-C) and Adolescents (PAQ-A). Instrument tersebut dimodifikasi kembali karena disesuaikan dengan kondisi dan kebiasaan melakukan aktivitas fisik di Indonesia. ${ }^{12}$

Analisis data yang digunakan yaitu uji Chi-Square dengan mengikutsertakan nilai odds rasio (OR) pada CI:95\%. Data hasil analisis disajikan dalam bentuk tabular dan tekstular. 


\section{HASIL DAN PEMBAHASAN}

\section{Karakteristik Subjek Penelitian}

Berdasarkan hasil penelitian yang dilakukan pada 62 mahasiswa Jurusan Gizi Politeknik Kesehatan Kemenkes Mataram, sebagaimana disajikan pada Tabel 1 menunjukkan bahwa sampel berusia dari 18 tahun sampai dengan 22 tahun dengan rata-rata usia mereka yaitu 19,3 tahun. Karakteristik berat badan mempunyai rata-rata sebesar $68,09 \mathrm{~kg}$ dan tinggi badan sebesar $155,4 \mathrm{~cm}$ dengan rata-rata Indeks Masa Tubuh (IMT) sebesar $28,17 \mathrm{~kg} / \mathrm{m}^{2}$.

Tabel 1. Karakteristik subjek penelitian pada Jurusan Gizi Politeknik Kesehatan Kemenkes Mataram $(n=62)$

\begin{tabular}{lcccc}
\hline \multicolumn{1}{c}{ Variabel } & Maksimum & Minimum & Rata-Rata & $\begin{array}{r}\text { Standar } \\
\text { Deviasi }\end{array}$ \\
\hline Usia (tahun) & 18,0 & 22,0 & 19,3 & 1,15 \\
Berat Badan $(\mathrm{kg})$ & 53,8 & 93,5 & 68,1 & 11,68 \\
Tinggi Badan $(\mathrm{cm})$ & 148,0 & 172,0 & 155,4 & 5,16 \\
IMT $\left(\mathrm{kg} / \mathrm{m}^{2}\right)$ & 23,6 & 41,0 & 28,2 & 4,53 \\
\hline
\end{tabular}

Rata-rata IMT yaitu sebesar $28,17 \mathrm{~kg} / \mathrm{m}^{2}$, dapat mengiterpretasikan bahwa secara umum mahasiswa di Jurusan Gizi Politeknik Kesehatan Mataram yang mempunyai usia 18 - 22 tahun adalah berkatagori gemuk.

Kelebihan berat badan hingga beberapa kilogram bisa menimbulkan risiko kesehatan yang tak bisa disepelekan. Kenyataannya, para remaja di Australia meningkatkan dugaan adanya risiko kesehatan yang akan muncul. Penemuan ini mengingatkan kita agar sadar terhadap adanya ancaman terhadap kesehatan masyarakat yang bisa berdampak terhadap penyakit tidak menular. ${ }^{13}$

Survei pemeriksaan kesehatan dan nutrisi nasional tahunan oleh Pusat Pengendalian dan Pencegahan Penyakit (CDC) menemukan bahwa
1 diantara 3 anak Amerika mengalami kegemukan atau berada dalam risiko menjadi gemuk. Totalnya sekitar 25 juta anak dan remaja Amerika mengalami kegemukan atau mendekati kegemukan. Sebanyak $18 \%$ remaja dan $25 \%$ orang dewasa di Indonesia mengalami obesitas. ${ }^{13}$

\section{Hubungan Aktifitas Fisik dengan Kejadian Obesitas}

Hasil penelitian (Tabel 2) menunjukkan bahwa remaja dengan aktifitas fisik yang ringan sebesar 55,2\% mengalami obesitas, sedangkan remaja dengan aktifitas fisik yang sedang terdapat sebesar $72,7 \%$ mengalami kegemukan pada usia 18 - 22 tahun di Jurusan Gizi Politeknik Kesehatan Kemenkes Mataram.

Tabel 2. Hubungan aktifitas fisik dengan kejadian obesitas (IMT) pada remaja di Jurusan Gizi Mataram

\begin{tabular}{|c|c|c|c|c|c|c|c|c|}
\hline \multirow{3}{*}{ Aktifitas Fisik } & \multicolumn{4}{|c|}{ Status Gizi Remaja (IMT) } & \multirow{2}{*}{\multicolumn{2}{|c|}{ Jumlah }} & \multirow{3}{*}{ Nilai $p$} & \multirow{3}{*}{$\begin{array}{c}\text { OR } \\
(\mathrm{CI}: 95 \%)\end{array}$} \\
\hline & \multicolumn{2}{|c|}{ Obesitas } & \multicolumn{2}{|c|}{ Gemuk } & & & & \\
\hline & $\mathrm{n}$ & $\%$ & $\mathrm{n}$ & $\%$ & $\mathrm{n}$ & $\%$ & & \\
\hline Ringan & 16 & 55,2 & 13 & 44,8 & 29 & 100,0 & 0,048 & 3,3 \\
\hline Sedang & 9 & 27,3 & 24 & 72,7 & 33 & 100,0 & & $(1,14-9,47)$ \\
\hline Jumlah & 25 & 40,3 & 37 & 59,7 & 62 & 100,0 & & \\
\hline
\end{tabular}

Selanjutnya hasil statistik menunjukkan bahwa terdapat hubungan signfikan (nilai $\mathrm{p}<$ $0,05)$ antara aktifitas fisik dengan IMT remaja mahasiswa di Jurusan Gizi Politeknik Kesehatan Kemenkes Mataram, dengan nilai $\mathrm{OR}=3,3$. Kondisi ini menunjukkan bahwa aktifitas fisik 
remaja yang ringan berpeluang sebesar 3,3 kali remaja akan mengalami obesitas dibandingkan dengan aktifitas fisik yang sedang.

Remaja di Jurusan Gizi Politeknik Kesehatan Kemenkes Mataram, rata-rata memiliki aktifitas fisik dengan kategori ringan. Aktifitas ringan responden tersebut seperti: lebih sering menghabiskan waktu dengan duduk berjam-jam memainkan smartphone, bermain komputer, menonton TV, belajar, kegiatan ekstrakurikuler, bersepeda, dan berenang. Mereka yang mempunyai aktivitas fisik ringan lebih banyak memiliki status gizi (IMT) dengan kategori obesitas. Remaja dengan aktifitas fisik yang rendah cenderung akan memiliki status gizi obesitas yang tinggi. Sedangkan pada hasil uji korelasi menunjukkan bahwa tidak ada hubungan antara aktifitas fisik dengan obesitas. Hal ini sesuai dengan penelitian yang dilakukan oleh Meiriyani tahun 2013, yang menyatakan bahwa tidak terdapat hubungan yang bermakna antara aktifitas fisik dengan obesitas. Sejalan dengan penelitan Anggraeny et al, menyatakan bahwa tidak terdapat hubungan yang bermakna antara asupan karbohidrat sederhana, lemak jenuh, dan aktivitas fisik. Kekuatan hubungan yang sangat lemah ditemukan antar semua variabel tersebut. ${ }^{14,15}$

Aktivitas fisik berkaitan dengan persentasi lemak tubuh terutama lemak viseral. Aktivitas fisik ringan akan memudahkan terjadinya penumpukan lemak tubuh. Proses timbulnya lemak di sekeliling tubuh berlangsung perlahan, lama dan seringkali tidak disadari. Orang obese menghabiskan lebih banyak energi untuk aktivitas fisik, namun bisa menunjukkan lebih sedikit aktivitas karena berat badan yang lebih besar, terutama aktivitas yang ringan. Beberapa faktor penentu peningkatan berat badan pada anak-anak dan remaja selain kebiasaan konsumsi makanan yang cenderung tinggi lemak dan kurang serat serta kurangnya aktivitas fisik. ${ }^{16}$

Kegiatan aktivitas fisik dapat dilakukan setiap hari sangat bermanfaat bagi kesehatan mental, hiburan dalam mencegah stres, bukan hanya untuk mendapatkan kondisi tubuh yang sehat. Rendahnya aktivitas fisik merupakan sangat signfikan terhadap kejadian kegemukan bahkan kejadian obesitas. Kebiasaan olahraga sangat penting, yang didasarkan atas aktivitas fisik anak dalam kesehariannya antara lain kebiasaan berjalan kaki dan bersepeda. Tidak rutinnya melakukan aktifitas fisik lebih memiliki risiko mengalami obesitas dibandingkan yang sering melakukan aktifitas fisik. Selain itu, remaja yang rutin dalam melakukan aktifitas fisik cenderung memiliki tubuh yang sehat dan berat badan yang ideal. ${ }^{17}$

\section{KESIMPULAN}

Remaja di Jurusan Gizi Politeknik Kesehatan Kemenkes Mataram mempunyai aktifitas fisik yang sedang dan rata-rata indeks masa tubuh (IMT) yaitu 28,2 atau secara umum remaja di Mataram adalah mengalami kegemukan. Aktifitas fisik remaja menunjukkan hubungan secara signifikan dengan indeks masa tubuh, dimana aktifitas fisik remaja yang ringan berpeluang sebesar 3,3 kali remaja akan mengalami obesitas dibandingkan dengan aktifitas fisik yang sedang.

Disarankan, pentingnya meningkatkan aktivitas fisik dan diperlukan penelitian lebih lanjut yang mempertimbangkan faktor lain yang berhubungan dengan kejadian obesitas misalnya pola konsumsi makan.

\section{DAFTAR PUSTAKA}

1. Claudia W, Marnelly TR. Konsep Diri Remaja Putri Obesitas. Jurnal Online Mahasiswa Fakultas Ilmu Sosial dan Ilmu Politik Universitas Riau. 2016;3(2):1-14.

2. Casey MM, Eime RM, Payne WR, Harvey JT. Using a socioecological approach to examine participation in sport and physical activity among rural adolescent girls. Qualitative health research. 2009;19(7):881-893. doi:https://doi.org/10.1177\%2F104973230 9338198.

3. Fitri Y, Mulyani NS, Fitrianingsih E, Suryana S. Pengaruh Pemberian Aktifitas Fisik (Aerobic Exercise) terhadap Tekanan Darah, IMT dan RLPP pada Wanita Obesitas. Aceh Nutrition Journal. 2016;1(2):105-110. 
doi:http://dx.doi.org/10.30867/action.v1i2.1 9.

4. Al Rahmad AH. Keterkaitan Asupan Makanan dan Sedentari dengan Kejadian Obesitas Pada Anak Sekolah Da sar di Kota Banda Aceh. Buletin Penelitian Kesehatan. 2019;47(1):67-76.

doi:https://doi.org/10.22435/bpk.v47i1.579.

5. WHO. Obesity and overweight. Facts about overweight and obesity. https://www.who.int/news-room/factsheets/detail/obesity-and-overweight. Published 2016. Accessed May 24, 2019.

6. Balitbangkes. Laporan Nasional Riskesdas 2018. Jakarta; 2018.

7. Hadi H. Gizi lebih sebagai tantangan baru dan implikasinya terhadap kebijakan pembangunan kesehatan nasional. Jurnal Gizi Klinik Indonesia. 2004;1(2):47-53.

8. Hendra C, Manampiring AE, Budiarso F. Faktor-Faktor Risiko Terhadap Obesitas Pada Remaja Di Kota Bitung. Jurnal eBiomedik. 2016;4(1):1-5. doi:10.35790/ebm.4.1.2016.11040.

9. Miko A, Pratiwi M. Hubungan Pola Makan dan Aktivitas Fisik dengan Kejadian Obesitas Mahasiswa Politeknik Kesehatan Kemenkes Aceh. AcTion: Aceh Nutrition Journal. 2017;2(1):1-5. doi:http://dx.doi.org/10.30867/action.v2i1.2 9.

10. Batara D, Bodhi W, Kepel BJ. Hubungan obesitas dengan tekanan darah dan aktivitas fisik pada remaja di Kota Bitung. Jurnal eBiomedik. 2016;4(1). doi:https://doi.org/10.35790/ebm.4.1.2016. 10842 .

11. Wulandari S, Lestari H, Fachlevy AF.
Faktor yang Berhubungan dengan Kejadian Obesitas pada Remaja di SMA Negeri 4 Kendari Tahun 2016. Jurnal Ilmiah Mahasiswa Kesehatan Masyarakat. 2017;1(3).

12. Kowalski KC, Crocker PRE, Donen RM. The physical activity questionnaire for older children (PAQ-C) and adolescents (PAQ-A) manual. College of Kinesiology, University of Saskatchewan. 2004;87(1):1-38.

13. Salam A. Faktor Risiko Kejadian Obesitas Pada Remaja. Jurnal MKMI. 2010;6(3):185190.

14. Novitasary MD. Hubungan antara aktivitas fisik dengan obesitas pada wanita usia subur peserta Jamkesmas di Puskesmas Wawonasa Kecamatan Singkil Manado. Jurnal e-Biomedik. 2014;1(2):1040-1046.

15. Anggraeny $O$, Ridhanti D, Nugroho FA. Tidak ada korelasi antara asupan karbohidrat sederhana, lemak jenuh, dan tingkat aktivitas fisik dengan status gizi pada remaja dengan kegemukan dan obesitas. AcTion: Aceh Nutrition Journal. 2018;3(1):1-8.

doi:http://dx.doi.org/10.30867/action.v3i1.8 9.

16. Suryana S, Fitri Y. Hubungan Aktivitas Fisik dengan IMT dan Komposisi Lemak Tubuh. AcTion: Aceh Nutrition Journal. 2017;2(2):114-119. doi:http://dx.doi.org/10.30867/action.v2i2.6 4.

17. Sartika RAD. Faktor risiko obesitas pada anak 5-15 tahun di Indonesia. Makara Kesehatan. 2011;15(1):37-43. 